Turpin, Shier, \& Scowen (2021)

\title{
ANSERJ
}

Vol. 12, No. 1

Spring / printemps 2021

pp. $82-106$

Canadian Journal of Nonprofit and Social Economy Research

Revue canadienne de recherche sur les OSBL et l'économie sociale

\section{Assessing the Social Impact of Mental Health Service Accessibility by a Nonprofit Social Enterprise: A Mixed-Methods Case Study}

\author{
Aaron Turpin \\ Factor-Inwentash Faculty of Social Work, University of Toronto \\ Micheal L. Shier \\ Factor-Inwentash Faculty of Social Work \\ Kate Scowen \\ Hard Feelings Mental Health
}

\begin{abstract}
The following study sought to examine the impact of a social enterprise mental health services model by assessing its influence on service accessibility and mental health stigma. A mixed-methods design was developed by collecting data from service users, counsellors, and community members of a social enterprise in Toronto, Ontario, using qualitative interviews and the Mental Health Knowledge Schedule (MAKS) survey. Findings show how the social enterprise increases service access and challenges mental health stigma by engaging in a variety of activities, including providing low-cost counselling, diversifying services, offering a positive and safe non-clinical environment, and engaging with the public directly with a storefront model. An analysis of data finds common themes and discrepancies between respondent groups. Insights on the replication of this social impact assessment model are discussed.
\end{abstract}

\section{RÉSUMÉ}

L'étude suivante visait à examiner l'impact d'un modèle de services de santé mentale d'entreprise sociale en évaluant son influence sur l'accessibilité des services et la stigmatisation liée à la santé mentale. Une conception à méthodes mixtes a été élaborée en recueillant des données auprès des utilisateurs de services, des conseillers et des membres de la communauté d'une entreprise sociale de Toronto, en Ontario, à l'aide d'entrevues qualitatives et de l'enquête Mental Health Knowledge Schedule (MAKS). Les résultats montrent comment l'entreprise sociale augmente l'accès aux services et remet en question la stigmatisation liée à la santé mentale en s'engageant dans une variété d'activités, y compris en fournissant des conseils à faible coût, en diversifiant les services, en offrant un environnement non clinique positif et sûr et en interagissant directement avec le public avec un modèle de vitrine. Une analyse des données révèle des thèmes communs et des écarts entre les groupes de répondants. Des informations sur la réplication de ce modèle d'évaluation de l'impact social sont discutées.

Keywords / Mots clés: Social entrepreneurship; Social enterprise; Nonprofit; Mental health; Community-based / L'entrepreneuriat social; Entreprise sociale; Non lucratif; Santé mentale; À base communautaire 


\section{Turpin, Shier, \& Scowen (2021)}

\section{INTRODUCTION}

Services addressing the mental health needs of vulnerable social groups in Canada are diverse. Many community-based nonprofit organizations have sought to alleviate issues pertaining to mental health by responding with wellness programs, such as counselling services (Jordans et al., 2019; Lamsal, Stalker, Cait, Riemer, \& Horton, 2018), peer and mutual-help groups (Sotskova, Woodin, \& St. Cyr, 2016; Turpin \& Shier, 2017), or arts-based programming (Bone, 2018; McKeown, Weir, Berridge, Ellis, \& Kyrarsis, 2016). However, nonprofits continue to grapple with meeting the demand for accessible services (Ganann et al., 2019; Knight \& Winterbotham, 2019), as service users are commonly faced with large wait-lists (Kowalewski, McLennan, \& McGrath, 2011; Lamsal et al., 2018) or poorly suited programs that are not capable of providing personalized support (Ibaraki \& Hall, 2014; Presley \& Day, 2019). Consequently, mental health services often fail to reach those who live on the margins of society (Curtis-Boles, 2019; Eamer, Fernando, \& King, 2017), primarily because programs are not capable of addressing the accessibility needs of this group (Pantalone, Scanlon, Brown, Radhakrishnan, \& Sprague, 2018; Sevelius, Patouhas, Keatley, \& Johnson, 2014). Mental health accessibility can be conceptualized as the ability to connect with mental health resources without prejudice or barriers (Ganann et al., 2019; Knight \& Winterbotham, 2019), and can include responding to a wide range of needs, including affordability (Corscadden, Callander, \& Topp, 2018; Phalen, 2016), identity and values alignment (Ibaraki \& Hall, 2014; Presley \& Day, 2019), and physical location (Corscadden et al., 2018).

One way nonprofits have addressed the issue of mental health accessibility is through socially entrepreneurial efforts (Hartley, 2017). Social entrepreneurship is defined by Zahra and Wright (2011) as "the activities and processes undertaken to discover, define, and exploit opportunities in order to enhance social wealth by creating new ventures or managing existing organizations in an innovative manner" (p. 68). Therefore, social entrepreneurship can be conceptualized as factors and characteristics that exist both at the organizational (Turpin \& Shier, 2019) and practice level (Olinsson, 2017) of human service organizations, and can include innovative, proactive, and market-based (i.e., activities that contribute directly to economic outcomes) activities combined with strategic risk-taking approaches (Turpin \& Shier, 2019).

Social entrepreneurship is conceptually distinct from social enterprise, though both terms share similar theoretical roots (Defourny \& Nyssens, 2010). As Defourny and Nyssens (2010) explain, social enterprise and social entrepreneurship are equally tied to the pursuit of a social mission (rather than a profit-seeking one) and work to maximize the social impact of an organization. However, a social enterprise model diverges from social entrepreneurship by engaging in the production of goods and services within the marketplace, which results in distinct economic risks that are not witnessed in other approaches to human service delivery (Defourney \& Nyssens, 2010). In sum, one specific way socially entrepreneurial nonprofits may engage in the pursuit of a social mission is through the creation of a social enterprise; however, this is not a requirement.

Though the social enterprise model is bourgeoning in Canada, research on these models remains incomplete and mostly outcomes-focused (Suchowerska et al., 2020). Consequently, it is incumbent on researchers to engage in the in-depth analyses of social enterprise models that seek to promote mental wellness, with a focus on identifying specific processes regarding how this approach may contribute to individual and structural outcomes. This study uses a case study methodology to examine a unique social enterprise model in Canada. Specifically, researchers partnered with a communitybased nonprofit social enterprise seeking to improve access to mental health services and applied a mixed-methods evaluation to measure the organization's social impact. This study was guided by three research questions: 1) How does [the social enterprise] improve access to mental health services for its service users? 2) What service-based factors associated with [the social enterprise] lead to a reduction in mental health stigma? 3) In what ways does [the social enterprise] storefront reduce stigma associated with mental health services? 


\section{Turpin, Shier, \& Scowen (2021)}

\section{BACKGROUND}

\section{Barriers to accessing mental health services}

Accessing mental health supports is often prevented by various barriers, including a societal stigma associated with mental health challenges and accessing related treatment. For example, research has shown that social groups (defined by culture, gender, and/or age) may perceive individuals experiencing mental health challenges in a negative way, which may lead these individuals to avoid seeking help (Knifton, 2012; Lee, Ditchman, Fong, Piper, \& Feigon, 2014; Lynch, Long, \& Moorhead, 2018; Saechao et al., 2012; Shannon, Wieling, Simmelink-McCleary, \& Becher, 2015; Yousaf, Grunfeld, \& Hunter, 2015). Consequently, many individuals avoid seeking mental health support due to fear of judgement from others (Auger, Abel, \& Oliver, 2018; Chen \& Kok, 2017; Hepworth \& Paxton, 2007; Martin, 2010).

Experiences of stigma have been shown to cause internalized self-judgement in individuals who experience symptomology, resulting in self-stigma and lower self-esteem (Corrigan, 2004). Conversely, studies have shown that individuals with either personal experience of mental health challenges and/or experience of mental health challenges within close social groups are more likely to hold lower stigmatizing views than those who do not have these experiences (Dyrbye et al., 2015; Morgan, Reavley, Jorm, \& Beatson, 2017; Pedersen \& Paves; Robinson \& Brewster, 2016). Other divergent effects may be witnessed among demographic groups. For example, some research suggests that men hold higher levels of mental health stigma than women (Brown, Moloney, \& Brown, 2018; Townsend, 2019), though similar studies purport no significant differences among gender, explaining that men and women hold equal stigmatizing attitudes (Earlise, Wiltshire, Detry, \& Brown, 2013; Elnitsky et al., 2013).

Literature has also identified that a failure to acknowledge problematic mental health symptomology will also pose barriers to seeking help. In a comparative study involving older and younger adults in the United States, Pepin, Segal, and Coolidge (2009) found that older adults were more likely to interpret symptoms of depression as non-problematic. Similar findings have been identified in other studies, resulting in individuals often ignoring issues that are otherwise treatable (Loewenthal, Mohamed, Mukhopadhyay, Ganesh, \& Thomas, 2012). In other cases, individuals may recognize there is a problem but not consider it serious enough to warrant mental health treatment (Chen \& Kok, 2017; Kne et al., 2017; Mosher et al., 2014). This may be due to a general lack of knowledge concerning mental health services (Hundt et al., 2018; Saechao et al., 2012), which is often impacted by poor access to mental health resources (Browne et al., 2019; Hundt et al., 2018; Pfeiffer et al., 2016). Acquiring accurate knowledge about the types and purposes of different available mental health services is commonly cited as a precursor to access (Schnyder et al., 2018; Wei, Carr, Alaffe, \& Kutcher, 2019). Yet, even when individuals are aware of mental health services, research shows that a lack of confidence in mental health providers can be another barrier to accessing help (Gaston, Earl, Nisanci, \& Glomb, 2016; Rughani, Deane, \& Wilson, 2011).

Research also cites logistical and programmatic barriers as preventing individuals from accessing services. Logistical barriers can include cost (Browne et al., 2019; Owens, Rogers, \& Whitesell, 2011), transportation (Browne et al., 2019; Hundt et al., 2018; Pepin et al., 2009; Pfeiffer et al., 2016), and lack of time (Browne et al., 2019; Hundt et al., 2018). Furthermore, service users may interpret available mental health supports as incompatible with non-Western cultures and, as such, not a viable means to address mental health concerns (Allen, Kim, Smith, \& Hafoka, 2016; Bettmann, Penney, Freeman, \& Lecy, 2015). For example, language has been considered a barrier, specifically in cases where service users lack the ability to communicate in the dominant language (Saha, Fernandez, \& Perez-Stable, 2007). Similarly, refugees in the United Kingdom commented on the unreliability of interpreters (Loewenthal et al., 2012), while refugees in the United States expressed fear that interpreters would break confidentiality (Shannon et al., 2015). 


\section{Turpin, Shier, \& Scowen (2021)}

\section{Social enterprise and mental health services}

Though contemporary social enterprise models providing health services began to emerge in North America in the early 1990s (Calò, Teasdale, Donaldson, Roy, \& Baglioni, 2018; Mandiberg, 2016) as a novel response to addressing disparities faced in the public health system (Macaulay, Roy, Donaldson, Teasdale, \& Kay, 2017), governments have only recently begun to formally acknowledge and emphasize the role these organizations play in supporting people experiencing serious adverse mental health symptomology (Buhariwala, Wilton, \& Evans, 2015). A similar rise in empirical interest about how social enterprise models may address health inequities has been witnessed over the past two decades (Suchoweska et al., 2020). It has been recognized that social enterprises providing health services continue to grow within competitive marketplaces in North America (Calò et al., 2019; Mandiberg \& Edwards, 2016), providing a complementary role to public health services (such as healthcare) through the use of innovative and adaptive market-based approaches. However, these health-oriented social enterprise organizations may differ from their public-sector counterparts in a few distinct ways, such as benefitting from more flexibility in program implementation, adopting personalized and service-user focused approaches, and developing lasting and meaningful connections between service users, staff, and community stakeholders (Calò et al., 2019). As a result, social enterprise models are often regarded as a complex form of public health intervention, expanding what may be considered as viable activities within this sector (Roy, Baker, \& Kerr, 2017).

Models of social enterprise have generally helped alleviate mental health inequities by addressing social problems through innovative interventions that improve social value (Kidd et al., 2015; Roy et al., 2014). The development of social enterprise in Canada is particularly relevant given increasing pressures on governments to increase efficiencies by contracting organizations to deliver social services (Chell, Nicolopoulou, \& Karataş-Özkan, 2010; McMurtry \& Brouard, 2015). Social enterprise may address these changes by mobilizing local resources to support marginalized populations while involving communities in helping to remove barriers that hinder social well-being (Smith \& Stevens, 2010). These approaches also promote self-sufficiency and efficiency, as they will generally redistribute profits back into the community (Defourny, 2004). Research conducted on the use of social enterprise for improving service access while scaling social impact reveals how these models are uniquely qualified to address mental health service inequities. For example, Fowler, Coffey, and DixonFowler (2019) describe a three-stage process in the development of a social enterprise: generating an idea by assessing social needs and assets in a community; developing the idea into an opportunity; and building and sustaining a social enterprise. The generation of an idea often originates from a group of citizens in a community who share well-defined goals based on shared experiences (Kernot, 2009). For instance, a collaboration between a university and a homeless youth agency in the United States led to the development of a socially entrepreneurial initiative that provides youth with vocational and clinical services to improve employment outcomes (Ferguson, 2012). This example provides a real-world application of social enterprise and demonstrates how it can be used to fit various contexts.

A vast majority of case examples and related research focuses on similar social enterprise models that pursue labour market reintegration as a means of supporting individuals experiencing mental health-related issues, contributing to their overall quality of life. Programs are often focused on addressing high unemployment levels (Krupa, Sabetti, \& Lysaght, 2019; Lysaght, Krupa, \& Bouchard, 2018) and barriers to inclusion for this service user group by providing employment skills and opportunities while challenging discrimination and stigma in the workforce (Buhariwala et al., 2015; Evans \& Wilton, 2019). This is often accomplished via the creation of spaces for service users to be employed in meaningful work and/or develop skills through a variety of experiences that contribute to employability (Buhariwala et al., 2015; Evans \& Wilton, 2019; Lysaght et al., 2018). In Canada, these skills typically include food preparation, landscaping, cleaning and janitorial services, retail, and packaging (Buhariwala et al., 2015; Evans \& Wilton, 2019). These social enterprise models are commonly referred to as work integration social enterprises (Krupa et al., 2019; Lysaght et al., 2018), and they have been found to reduce stigma by increasing public perceptions regarding the legitimacy, value, and competence of persons experiencing a mental health issue. 


\section{Turpin, Shier, \& Scowen (2021)}

There exists some evidence linking participation in health-focused social enterprise programming to specific outcomes of personal well-being among social service users. These outcomes can broadly be categorized as contributing to physical health (including positive health behaviours and physical well-being), mental health (including increased sense of purpose and meaning, motivation, goal orientation, empowerment, confidence, positive coping, resilience, life satisfaction, family and peer support, self-esteem, self-worth, and dignity), and social determinants (including increased social capital, sense of community, trust and safety, employability, and access to services alongside reduced stigmatization) (Calò et al., 2018, 2019; Macaulay et al., 2017; Roy et al., 2014; Roy et al., 2017). Specific aspects of programs have been identified as contributing to the overall efficacy of these outcomes, such as increased collaboration with community and public organizations (Calò et al., 2018; Phillips et al., 2015). There are already a number of social enterprises outside of Canada that are demonstrating the possibilities of improving access to mental health services by engaging in collaborative processes. In the United Kingdom, several culturally specific organizations were created to provide diverse counselling services that are delivered by staff drawing from their own experience (Fernando, 2005; Palmer \& Ward, 2007). Similarly, another U.K.-based social enterprise, the Wellbeing Service, has adopted the goal of improving access to psychotherapy by providing services in informal social settings to assist individuals in rebuilding social connections while referring them to resources and providing psychoeducation (Hartley, 2017). These interventions have not only proven to be impactful and sustainable but also hold promise as service models that can be scaled broadly (Hartley, 2017). Other aspects of social enterprise models that may impact outcomes include organizational size, location, and staff (Roy et al., 2014).

Though existing research has begun to identify the impact of social enterprises engaged in mental health services, it has done a poor job at ascertaining specific ways in which these unique organizational forms accomplish these outcomes (Suchowerska et al., 2020). Some possible processes identified in conceptual and qualitative research include examining the role of education and skills development, (Macaulay et al., 2017; Roy, 2017), exploring social interaction (Farmer et al., 2017), and looking at the development of a positive and safe service environment (Calò et al., 2018; Farmer et al., 2017; Macaulay et al., 2017; Roy et al., 2017). These processes follow the conceptualization of social enterprise as spaces of well-being (Munoz, Farmer, Winterton, \& Barraket, 2015), where services adopt a multipronged approach to how well-being is created and maintained (i.e., spoken, felt, and practiced). These processes may simultaneously address various well-being issues, such as loneliness and isolation (Munoz et al., 2015). However, a greater need for boundaryspanning research that connects these processes to the broader community is needed, especially studies that incorporate multiple perspectives (including service users and community members) (Farmer et al., 2016). Relatedly, rigorous mixedmethod designs are required to develop a deeper understanding of how outcomes are achieved (Macaulay et al., 2017; Roy et al., 2014), including the role of organizational activities and functioning in the overall development of services (Suchowerska et al., 2020). This study responds to these gaps by employing a mixed-methods case study design. Specifically, the research aims to understand how a nonprofit social enterprise may address mental health stigma and barriers to access through its program design and implementation. Perspectives gathered from service users, staff, and community members are compared to provide a fulsome description of service experiences and engagement with the public, while survey data on demographics and stigma are analyzed.

\section{Case example}

The case example used in this study is a three-year-old nonprofit social enterprise located in Toronto, Canada, that aims to address issues of mental health service access by serving two main functions: 1) providing the physical space for and supporting the practice of a group of counsellors and therapists who offer services for a broad range of needs; and 2) creating a retail space that offers curated resources and products that promote well-being. Both aspects of the social enterprise contribute to an entrepreneurial social service approach where profits from retail sales at the storefront are directly channelled into supporting the community of practice. Attached to the storefront space are offices where private practitioners provide short-term therapy (50-60 minutes for a maximum of 12 sessions, with the option of three booster sessions) 


\section{Turpin, Shier, \& Scowen (2021)}

for services users, who self-select their rate from a sliding scale. This model is sustainable, as the social enterprise collects steady profits from the storefront, charges monthly office rental fees, and receives a few modest private donations and other grants from partnership organizations (such as the counselling department at a local university).

Though the organization has successfully implemented a social enterprise that has seen considerable growth in just three years (resulting in an increasing demand to expand to another site), it has not yet been able to assess, in a more systematic way, how it achieves its main goals as an organization; namely, to increase access to mental health counselling services and to reduce the stigma associated with these services. To answer these questions, a mixed-methods evaluation of social impact was designed and implemented.

To supplement the qualitative inquiry, researchers developed hypotheses to be tested quantitatively. Researchers were interested in how engagement with the storefront might impact mental health stigma. Following research findings cited in the literature review, some studies (Schnyder et al., 2018; Wei, Carr, Alaffe, \& Kutcher, 2019) show how increased mental health knowledge can reduce stigmatizing attitudes toward help-seeking behaviour among a variety of social groups. A similar effect may be measured by testing whether or not the number of visits to the social enterprise storefront contributes to more positive perceptions of mental health service use. This is because the products in the storefront include various stigma-reducing items, including books, zines, and other educational material designed to shape positive perceptions of mental health and related supports. Therefore, the following hypothesis was developed:

Hypothesis 1: Increased engagement with the social enterprise storefront is inversely associated with mental health service stigma.

A second variable identified in the literature review as a salient contributor to reducing mental health stigma is experience with mental health issues, both personally (Dyrbye et al., 2015; Pedersen \& Paves, 2014) and/or with a close family member or friend (Morgan, Reavley, Jorm, \& Beatson, 2017; Robinson \& Brewster, 2016). Related personal experiences provide insight into challenges associated with mental health (Conchar \& Repper, 2014; Oats, Drey, \& Jones, 2017), often leading to a more compassionate perception of people who seek support for mental wellness (Robertson, Carpenter, Donovan-Hall, \& Bartlett, 2019). Conversely, research on the effect of having a family member or close friend with a mental health issue and its impact on stigmatizing perceptions is less clear, but it offers some insight into how personal relationships may educate and increase one's awareness of related issues (Griffiths, Crisp, Barney, \& Reid, 2011). Based on these findings, the following hypotheses were developed:

Hypothesis 2: Respondents who have experienced adverse mental health issues will have significantly lower mental health service stigma than those who have not.

Hypothesis 3: Respondents who have a friend or family member who experienced mental health issues will have significantly lower mental health service stigma than those who do not.

\section{METHODS}

This study adopts a case study-mixed-methods (CS-MM) design, where researchers have employed a parent case study utilizing a mixed-methods approach (Guetterman \& Fetters, 2018). Mixed-methods research utilizes both quantitative and qualitative methodology in one study, integrating them through all phases (Creswell, 2015), while a case study is defined as the deep investigation of a real-life case, or multiple cases, to better understand its complexity (Yin, 2014). The case itself is understood as a manifestation of a larger phenomenon under study (Onghena, Maes, \& Heyvaert, 2019) that can be examined in detail by investigating how it is represented within one or more specific cases (Yin, 2014). For this study, researchers chose a single unit of analysis (the social enterprise) and collected multiple sources of data to examine the case from different angles. 


\section{Turpin, Shier, \& Scowen (2021)}

The CS-MM design has been utilized in other social science research (Guetterman \& Mitchell, 2016; Little, Motohara, Miyazaki, Arato, \& Fetters, 2013; Onwuegbuzie \& Leech, 2010) and is applied in this study following a methodological structure, as outlined by Guetterman and Mitchell (2016). Researchers chose a single case study design to provide an in-depth analysis of a novel social enterprise model addressing mental health accessibility and stigma. Since a single case study generally adopts a single unit of analysis, it is uniquely qualified to explore a phenomenon with greater precision and nuance (Yin, 2014), compared to multi-site designs, which may lack this ability due to larger and more varied samples. The ability to conduct deep analysis via case study design directly supports the overall aim of the research: to understand how a nonprofit social enterprise may address mental health stigma and barriers to service access through its program design and implementation.

\section{Procedure}

To answer the research questions identified in the introduction, researchers collected qualitative data from three groups (service users, counsellors, and community partners) while concurrently gathering survey data from consumers (i.e., community members). Qualitative data sources were used to triangulate findings (Yin, 2014) for research questions one and two, while survey data and further qualitative inquiry were used to answer research question three. This is also known as an embedded case study analysis (Guetterman \& Fetters, 2018), where multiple data sources are used to answer the same research questions to provide a more complete understanding of the case. The triangulated approach is most novel, as the majority of research adopting a CS-MM design do not include multiple qualitative sources (Guetterman \& Fetters, 2018), despite recommendations to do so (Yin, 2014). Before data collection, researchers obtained ethics review and certification from the University of Toronto Health Sciences Research Ethics Board.

\section{Sampling and participants}

Sampling in case studies is generally examined at two levels: choosing the case itself and selecting participants (Guetterman \& Fetters, 2018). To achieve data triangulation (Yin, 2014), three participant groups were selected for the study: 1 ) service users ( $n=55)$; 2 ) counsellors and community partners $(n=28)$; and 3$)$ community members/consumers $(n=95)$. Quantitative survey data from the sample of community members/consumers $(n=95)$ purchasing products in the storefront was also employed. Service users were selected using convenience sampling and were recruited by counsellors renting counselling space at the social enterprise. Specifically, counsellors were provided training on how to select and recruit service users safely, including information on the study itself and guidance on selecting respondents who were deemed low-risk research participants. Counsellors then utilized their clinical judgement to select eligible service users, offering them the opportunity to participate in the research after the service user completed counselling services, while clearly articulating to the service user that there was no expectation of participation (informed consent), participation would not affect their future engagement with the social enterprise, and service user participation was anonymous and confidential. This procedure reflects a purposive sampling method, and it was chosen to protect the safety of service user participants. Counsellors were recruited via email that included study information and informed consent. The email was sent to all counsellors working at the social enterprise, as well as counsellors that provide referrals from partnering mental health organizations and hospitals. This was done to collect a broad range of input from mental health workers on each side of service engagement. All counsellors renting space at the social enterprise, as well as referring counsellors, were contacted for participation in the study. This procedure also reflects a purposive sampling method, in that all eligible respondents were provided with an opportunity to participate in the study. This approach was adopted to maximize the number of respondents in this sample group. Finally, community members were recruited using convenience sampling and were given information about the survey when they visited the store. Convenience sampling was adopted as the most pragmatic approach to recruiting community members given the context (a storefront on a busy commercial street) and the invariability with which community members visited the storefront and had interactions with staff. The social enterprise also advertised the study to community members on its website and social media channels, including embedded 


\section{Turpin, Shier, \& Scowen (2021)}

links to the survey. There were no incentives for any respondent group to participate in this study, and all engagement proceeded only after an informed consent process.

\section{Data collection and measures}

To collect qualitative data, researchers developed interview guides for each of the respondent groups following the research questions. Interview guides included similar questions for each group related to program efficacy, access, barriers, and improvements, but the questions were specifically worded for each respondent group. All respondent groups provided responses in an online survey that was created using Qualtrics software (Qualtrics, 2020) and accessed via a secure link. Response fields did not limit the word count. Researchers chose to include all aspects (qualitative and quantitative) of data collection on the same online survey to increase access for the study participants. This allowed respondents to engage with the research at a time and pace that was most conducive to their individual needs. It allowed researchers to better access participant groups that they may have experienced difficulties in engaging in-person. Providing a fully digital survey and questionnaire has been cited as one strategy for engaging with hard-to-reach groups, such as counsellors, service users, and community members (Van Wijk, 2014; UyBico, Pavel, \& Gross, 2007).

For the quantitative analysis, survey data were collected from community members (i.e., members of the public who engaged with the social enterprise storefront) using an online survey via secure link from Qualtrics (Qualtrics, 2020) software. The quantitative survey consisted of two main sections: a range of demographic questions, and questions from a stigmarelated measure in the Mental Health Knowledge Schedule (MAKS) (Evans-Lacko et al., 2010).

\section{The Mental Health Knowledge Schedule (MAKS)}

This subscale originally included six items assessing attitudes about mental health and treatment, including medication, interventions, and recovery (see Table 1 for a full list of items), which are measured on a six-point ordinal scale: Agree strongly, Agree slightly, Neither agree nor disagree, Disagree slightly, Disagree strongly, Don't know. Researchers collected data from community members $(n=95)$ using this metric and performed a reliability test of internal consistency and confirmatory factor analysis to assess the overall construct validity of the subscale. Results using the full six-item measure revealed substandard model fit, and, therefore, items five and six were removed to improve overall validity. Final model results testing a four-item factor of mental health stigma indicated good overall validity $(X 2=24.245, d f=23$, $p=0.3903, \mathrm{TLI}=0.958, \mathrm{CFI}=0.972, \mathrm{RMSEA}=0.030)$. A reliability analysis of the four-item factor using Cronbach's alpha demonstrated moderate reliability (0.64).

\section{Table 1. MAKS scale items}

\begin{tabular}{|l|l|}
\hline Variable & Item \\
\hline MAKS_1 & Most people with mental health problems want to have paid employment. \\
MAKS_2 & If a friend had a mental health problem, I know what advice to give them to get professional help. \\
MAKS_3 & Medication can be an effective treatment for people with mental health problems. \\
MAKS_4 & Psychotherapy (e.g., talking therapy or counselling) can be an effective treatment for people with mental health problems. \\
\hline
\end{tabular}

To answer Hypothesis 1 (which states that increased engagement with the social enterprise storefront is inversely associated with mental health service stigma), researchers selected two variables measuring previous experience with the social enterprise, including shopping at the storefront and utilizing counselling services, which they addressed through 


\section{Turpin, Shier, \& Scowen (2021)}

two questions: 1) How many times have you visited the social enterprise storefront? 2) Have you received counselling services from the social enterprise, either currently or in the past? Due to the close proximity of the counsellor's offices to the storefront (i.e., in the same building), it can be reasonably assumed that some customers would be current or previous service users, and it was important to capture this as a possible confounding factor. To answer hypotheses two and three (which state that respondents who have experienced adverse mental health issues will have significantly lower mental health service stigma than those who have not, and that respondents who have a friend or family member who has experienced mental health issues will have significantly lower mental health service stigma than those who do not), researchers asked respondents about their personal experiences of mental health, as well as experiences with family and close friends who experienced a mental health issue, using two binary (yes/no) variables: 1) Have you experienced adverse mental health issues before? 2) Have you had a friend or family member who has experienced mental health issues in the past?

Finally, three other demographic variables were included in the community member survey: age, gender, and level of education. Recent research (see literature review) has revealed conflicting evidence on each of these variables and their effect on mental health stigma (Brown, Moloney, \& Brown, 2018; Earlise et al., 2013; Elnitsky et al., 2013; Holman, 2014; Townsend et al., 2019). They are included in this study as potential confounding variables.

\section{Data analysis}

Researchers analyzed qualitative data by adopting a thematic qualitative approach (Creswell, 2009; Miles \& Huberman, 1994). Thematic analysis conceptualizes findings by developing general and specific themes through the grouping (i.e., coding) of same or similar data (Creswell, 2009; Miles \& Huberman, 1994). Researchers selected this approach for the purpose of identifying detailed aspects of the social enterprise that provide responses to the research questions. To accomplish this, data were compiled by question and separated by respondent group. Researchers left data categorized by question for the purpose of keeping the analysis directly relevant to specific aspects of the social enterprise (e.g., improvements to services or successful elements of the programs). Then, researchers independently coded the data by arranging responses into common groups, known as general themes (Glaser \& Strauss, 1967). These themes were cross-referenced between researchers to identify discrepancies, which were accounted for until researchers agreed on same or similar themes. A second round of analysis subjected each general theme to further coding, generating subthemes that were again cross-referenced for the same purposes. This technique follows constant comparison (Hsieh \& Shannon, 2005) and content analysis (Goetz \& Lecompte, 1984) methods.

Beyond generating general and specific themes, researchers wanted to further qualify how these themes were represented in the data. To achieve this, they used the final general themes and re-assessed the data to quantify how many times each theme appears within transcripts. The resulting data shows the amount to which each theme appears in the data, both in the number of times it is mentioned by respondents (demarked by $n$ ), as well as the overall percentage for the question.

To answer research question three, the modified measure of MAKS was entered into a regression model as the dependent variable. Predictor variables included demographic information (storefront visits, service use, personal experiences with mental health, family/friend experiences with mental health, age, gender, and level of education). Researchers tested for significant relationships at the $p=<.05$ level. As well, descriptive statistics for the MAKS scale and demographics were completed.

\section{Findings}

Tables 2, 3, and 4 provide summaries of thematic analysis for each respondent group by question. 
Table 2. Survey questions and thematic analysis for service users $(n=55)$

1) What are some of the barriers you have experienced in the past that have prevented you from accessing mental health treatment?

\begin{tabular}{|c|c|c|c|}
\hline Code & Sub-codes & $n$ & $\%$ \\
\hline Cost & Cost of living; financial precarity; therapist rates; financial support & 27 & 31 \\
\hline Availability & Cultural/language compatibility; working hours & 20 & 23 \\
\hline Fear/apprehension & Fear of judgement; stigma; admitting to requiring help & 12 & 14 \\
\hline Location & Closeness to work and home & 10 & 11 \\
\hline Therapist/therapy match & Matching therapy type and service framework to needs & 9 & 10 \\
\hline Lack of knowledge & Unsure how to find therapist; unsure of types of therapy & 6 & 7 \\
\hline Wait-list & Long wait times for services & 4 & 4 \\
\hline
\end{tabular}

2) Thinking about the barriers you identified in the previous question, how has this impacted your life?

\begin{tabular}{llcc}
\hline \multicolumn{1}{c}{ Code } & \multicolumn{1}{c}{ Sub-codes } & $n$ & $\%$ \\
\hline Inability to cope/work & Inability to get work done/engage in social activities & 24 & 37 \\
Lack of access to services & Inadequate insurance; previous bad experiences with treatment & 16 & 25 \\
Impacts relationships & Inability to be emotionally vulnerable; unhealthy relationships & 14 & 22 \\
Feeling helpless/alone & No emotional outlet; anxiety due to incurring debt & 6 & 9 \\
Unable to move forward & Lack of ambition/energy; low self-esteem; frustration & 4 & 7 \\
\hline
\end{tabular}

3) What are some of the ways that [the social enterprise] has improved your access to mental health services?

\begin{tabular}{llcc}
\hline \multicolumn{1}{c}{ Code } & \multicolumn{1}{c}{ Sub-codes } & $n$ & $\%$ \\
\hline Affordability & Lessening financial stress & 38 & 43 \\
Overall accessibility & Multiple service options; central location; low service restrictions & 20 & 23 \\
Open service environment & Warm/friendly space; not feeling judged; non-clinical environment & 9 & 10 \\
Positive social impact & Improved hopefulness/self-awareness; healthy relationships & 9 & 10 \\
Quality of services & Positive staff interactions; personal values alignment & 6 & 7 \\
Links to other services & Service navigation; referrals/ongoing care; information hub & 6 & 7 \\
& & & \\
\hline
\end{tabular}

4) How can [the social enterprise] continue to improve access to mental health services?

\begin{tabular}{llll}
\hline \multicolumn{1}{c}{ Code } & \multicolumn{1}{c}{ Sub-codes } & $n$ & $\%$ \\
\hline Scale up services & More sessions/locations/service options & 19 & 34 \\
Program flexibility & Evening/weekend hours; remote counselling & 16 & 28 \\
Providing resources & Online directory; social media; bridging services & 11 & 20 \\
Raising awareness & Increased advertising; promoting in other venues & 10 & 18 \\
\hline
\end{tabular}


Table 3. Survey questions and thematic analysis for counsellors $(n=28)$

1) How does the social enterprise impact your ability to provide services?

\begin{tabular}{llcc}
\hline \multicolumn{1}{c}{ Code } & \multicolumn{1}{c}{ Sub-codes } & $n$ & $\%$ \\
\hline Long wait-lists & Closed wait-lists; impact on wait times & 24 & 50 \\
Service efficiency & Quick access from intake to counsellor & 16 & 33 \\
Mental health supports & Diverse services addressing needs & 8 & 17 \\
\hline
\end{tabular}

2) How does the social enterprise impact access to services for the population you work with?

\begin{tabular}{llll}
\hline \multicolumn{1}{c}{ Code } & \multicolumn{1}{c}{ Sub-codes } & $n$ & $\%$ \\
\hline Timely access & New/viable option to choose from & 24 & 50 \\
Affordable services & Uncostly and quality service & 24 & 50 \\
& & & \\
\hline
\end{tabular}

3) What are some of the barriers that have prevented clients from accessing mental health services?

\begin{tabular}{llcc}
\hline \multicolumn{1}{c}{ Code } & \multicolumn{1}{c}{ Sub-codes } & $n$ & $\%$ \\
\hline Cost/income & Unaffordable service fees; lack of insurance coverage & 18 & 39 \\
Lack of services/fit & Location; physical space; culturally appropriate & 12 & 26 \\
Wait time & Long wait-lists for services & 11 & 24 \\
Stigma & Institutional oppression; public stigma & 5 & 11 \\
& & \\
\hline
\end{tabular}

4) Thinking about the barriers you identified in the previous question, how has this impacted your practice?

\begin{tabular}{llcc}
\hline \multicolumn{1}{c}{ Code } & \multicolumn{1}{c}{ Sub-codes } & $n$ & $\%$ \\
\hline Overall increased access & Affordability; motivated clients & 17 & 54 \\
Managing wait-lists & Early intake; triaging services & 7 & 23 \\
Serving clients better & Positive rapport; crisis-based therapy; referrals & 7 & 23 \\
\hline
\end{tabular}

5) How can the social enterprise continue to improve access to mental health services?

\begin{tabular}{llcc}
\hline \multicolumn{1}{c}{ Code } & \multicolumn{1}{c}{ Sub-codes } & $n$ & $\%$ \\
\hline Scale up services & More sessions; open new locations; more counsellors & 14 & 55 \\
Diversify services & Hire racialized counsellors; group therapy & 9 & 30 \\
Standardize services & Standardized assessments; standardized referrals & 6 & 15
\end{tabular}




\section{Turpin, Shier, \& Scowen (2021)}

Table 4. Survey questions and thematic analysis for community members $(n=95)$

1) What impact has [the social enterprise] had on your neighborhood?

\begin{tabular}{llll}
\hline \multicolumn{1}{c}{ Code } & \multicolumn{1}{c}{ Sub-codes } & $\mathrm{n}$ & $\%$ \\
\hline Inclusive/welcoming space & Normalizing therapy; creates community & 37 & 36 \\
Access to services & Central location; intensive services & 30 & 29 \\
Provides resources & Informative products; self-care items & 23 & 22 \\
Raises awareness & Challenging stigma; opening mental health dialogue & 13 & 13 \\
& & & \\
\hline
\end{tabular}

2) Why have you chosen to shop at [the social enterprise]?

\begin{tabular}{llll}
\hline \multicolumn{1}{c}{ Code } & \multicolumn{1}{c}{ Sub-codes } & $\mathrm{n}$ & $\%$ \\
\hline Support community & Support local business/services; personal values & 36 & 35 \\
Resources/products & Quality products; helpful/supportive resources & 34 & 33 \\
Receiving services & Comfortable space before/after counselling & 20 & 20 \\
Recommended & Recommended by friend/family & 12 & 12 \\
& & \\
\hline
\end{tabular}

3) What aspects of the social enterprise storefront do you find most valuable?

\begin{tabular}{llll}
\hline \multicolumn{1}{c}{ Code } & \multicolumn{1}{c}{ Sub-codes } & $\mathrm{n}$ & $\%$ \\
\hline Products & Variety of items; de-stigmatizing; local/ethical & 37 & 35 \\
Open environment & Approachable staff; positive interactions & 27 & 26 \\
Information/knowledge & Learning about mental health/services & 22 & 21 \\
Mental health services & Learning about services/organization & 18 & 18
\end{tabular}

How does the social enterprise improve access to mental health services for its service users?

Before discussing how the social enterprise improves access to mental health services, service users and counsellors were asked to identify some of the largest barriers to service that individuals seeking help commonly encounter. Overwhelmingly, the high costs associated with counselling services were cited as a primary barrier to seeking support. This included the increased cost of living due to requiring support for mental health, unaffordable rates for talk therapy, living in a precarious financial situation (which is perpetuated by unaddressed mental health needs), and receiving financial support from family and/or friends. One service user captured how issues associated with mental health can have an impact on both financial stability and service access:

It's a weird position to be in where part of your illness is not having enough money to live and being told that you

should pay 150 dollars a week to be okay. In my case, it's cheaper to sedate myself with pot. (Service user \#9)

Counsellor and service availability was also a primary issue affecting access to mental health services. This included finding services with the appropriate cultural and language practices, finding services beyond traditional working hours, how well service users felt the therapy service responded to their needs, how the service created a safe space for service users, how many sessions were offered, and how well the service framework and philosophy upheld by the counsellors and organization matched those of the service users. 


\section{Turpin, Shier, \& Scowen (2021)}

One factor relating to access that was identified by service users and not counsellors was a general lack of knowledge regarding how to begin the process of engaging with mental health services. Service users explained that they were unsure of how to find a therapist and did not know about different types of therapy or what might be suitable for them. Analysis also revealed a discrepancy between the frequency with which counsellors and service users cited wait times as a barrier to service access. Specifically, counsellors mentioned this issue a total of 11 times (or $24 \%$ of the data for this question), while for service users it only appeared in the data at a rate of four percent $(n=4)$. This problem was mostly attributed to the long wait-lists commonly found in more affordable mental health counselling services.

The social enterprise was found to address many of these barriers in a variety of ways. Service users and counsellors most commonly identified how the social enterprise addressed high service costs by offering therapy at an affordable rate, commenting on how the sliding-scale system lessened financial stress while providing a limited, yet adequate, amount of sessions. Counsellors likened the cost structure offered at the social enterprise to opening service access for service users with economic barriers (such as having little or no insurance coverage), which in turn reduced caseloads for other service providers as users were provided with quick referrals.

Service users also identified an increase in general access to services when participating in the social enterprise programs. Aspects of the program that supported this theme included an abundance of service options (such as counsellors, therapeutic interventions, and support offered for a range of challenges), the centralized location of the social enterprise, and low program eligibility requirements. A general increase in access to services was also perceived by community members, who discussed how quick and affordable counselling, combined with a central location and intensive services, supported the accessibility of the social enterprise. One community member commented on this experience:

It destigmatizes therapy by making anyone feel invited and welcome to come into the space, browse beautiful and local goods, and think about how approachable therapy can be. (Community member \#78)

Counsellors identified similar program characteristics while explaining how service efficiency (i.e., the period between the first engagement with the social enterprise to meeting with a counsellor) and various mental health supports increased access. Of primary concern for counsellors, however, were the long wait-lists associated with the social enterprise services. Some external healthcare providers explained that wait-list availability had gradually decreased over time as the social enterprise became more popular and managed a larger portion of referrals. This resulted in an abundance of closed waitlists and fewer options for service users. Many counsellors commented that short wait-lists no longer existed at the social enterprise and that the program no longer had an impact on reducing wait times. One counsellor discussed this problem:

When [the social enterprise] first started, it greatly impacted wait-times and access to service. Unfortunately, as their profile has grown in the last year, it has become difficult to refer as ... counsellors seem to mostly maintain closed wait-lists. (Counsellor \#19)

Another aspect included how the social enterprise provided valuable links to similar services while offering excellent mental health resources, including support with navigating external services, being provided with referrals, and using the social enterprise as a hub for information and resources. Community members felt as though this aspect of the social enterprise was even more effective in increasing service access and identified that the social enterprise provides resources such as zines, books, cards, and self-help items that are readily available to the public. Similarly, community members identified the curated mental health products available in the storefront to be impactful and enjoyed the variety of items to browse, including unique local and ethical goods. These products were perceived to be personalized.

The quality of services itself was an important supportive factor in improving access, as found in the data for service users and counsellors. Service users discussed that the quality of services was achieved in part by positive interactions with staff and a personal values alignment between themselves and the counsellor and/or organization. Counsellors 


\section{Turpin, Shier, \& Scowen (2021)}

found the personalization of programs was an important factor contributing to service quality, indicating that service user choice in counsellor added to their autonomy, as did the flexibility in services, which offered many specialized and targeted approaches that could meet service user needs. However, counsellors also indicated incompatible programming at the same rate, stating that many counsellors were no longer available and suggesting that the social enterprise may not be well known to other services.

What service-based factors associated with the social enterprise lead to a reduction in mental health stigma?

Service users did not hesitate to explain how widely held social attitudes related to mental health prevented service access. For example, service users explained how fear and apprehension about mental health services contributed to a hesitation to seek help, including a fear of judgement by others for seeking mental health support, challenges with admitting that help was required, and feeling as though their problems were not suitable for counselling. Counsellors more commonly related this issue to a broadly held stigma associated with mental health services that caused service users to feel as though they could not move forward in seeking help.

All respondent groups referenced the comfortable service environment provided by the social enterprise as increasing accessibility. For example, counsellors highlighted how the friendly and nonjudgemental environment provided a safe and supportive place to conduct mental health services. This theme was also found in the community data, appearing in responses to two separate questions. When asked about how the social enterprise impacted the local neighbourhood, community members mentioned how the creation of an inclusive and welcoming space helped to normalize mental health services by creating a community space with a pleasing aesthetic. Supporting these findings, once counsellor commented:

This enhances its appeal as a place to get help because if feels less intimidating and more appropriate for a lot of people than a medical clinic or hospital setting. This has made it much easier for me to support people who would otherwise not have access to support. (Counsellor \#43)

Service users alone described how the social impact of the programs contributed to service access by changing the way they perceived the mental health system. For example, service users described how the programs led to improved hopefulness in their ability to achieve mental wellness, leading to further engagement in services. As well, the adoption of healthy coping strategies and self-awareness skills supported a stronger belief in therapeutic interventions. Service users also cited the impact of positive therapeutic relationships in supporting continuous involvement in mental health services.

How does the social enterprise's storefront reduce stigma associated with mental health services?

Researchers asked community members how the social enterprise contributed to their awareness of and engagement with mental health services. Respondents stated that the storefront provided valuable information and knowledge, including mental health-based resources, that increased public engagement. These resources supported raising awareness about mental health services by generating dialogue about mental health-related issues and challenging common and misinformed ideas relating to mental health. Many community members commented on how the resources supported positive and realistic depictions of mental health.

Researchers were also interested in understanding why community members chose to shop at the storefront and what aspects might have contributed to community members' engagement with the social enterprise. A large amount of data was attributed to community members' desire to support the broader community by engaging with the social enterprise. Specifically, respondents explained that supporting local business and low-cost mental health services aligned with their personal values. Relatedly, community members identified that the unique resources and products offered at the social enterprise provided a selection of positive mental health merchandise that could be purchased while shopping at the storefront. Thus, shopping at the social enterprise reflected more altruistic motivations that provided an opportunity for 


\section{Turpin, Shier, \& Scowen (2021)}

community members to easily participate in a local venture with a social mission. This theme was captured in the response from one community member:

I wanted to support a business with a strong dedication to mental health awareness and services. I feel that [the social enterprise] is really breaking the boundaries of what a business should be. (Community member \#107)

Community members also appreciated how the storefront offered a friendly and open environment. Importantly, community members seemed to enjoy interpersonal interactions with knowledgeable and approachable staff in the storefront, as well as with other members of the public.

Demographic statistics of the study sample are shown in Table 5. Descriptive statistics for the MAKS scale items, as well as the latent factor of mental health stigma, are shown in Table 6. Mean scores for items are largely oriented toward the Agree strongly and Agree slightly response categories, and the only item with a mean score over two was MAKS_2 ("If a friend had a mental health problem, I know what advice to give them to get professional help"). The mean score for the latent factor of mental health stigma was $1.59(S D=0.75)$. There were no significant relationships found between demographic variables and mental health stigma in the regression analysis. Therefore, hypotheses one, two, and three were not supported.

Table 5. Demographic statistics of the study sample

\begin{tabular}{|c|c|c|c|}
\hline Variable & $\begin{array}{l}\text { Number } \\
(\%)\end{array}$ & Mean & $\begin{array}{c}\text { Standard } \\
\text { deviation } \\
(S D)\end{array}$ \\
\hline \multicolumn{4}{|l|}{$\begin{array}{l}\text { Received services from } \\
\text { the social enterprise in the past }\end{array}$} \\
\hline Yes & $55(59.1)$ & & \\
\hline No & $38(40.9)$ & & \\
\hline Missing & 2 & & \\
\hline \multicolumn{4}{|l|}{ Highest education achieved } \\
\hline High school & $4(4.3)$ & & \\
\hline College/undergraduate & $56(60.9)$ & & \\
\hline Graduate & $32(34.8)$ & & \\
\hline Missing & 3 & & \\
\hline \multicolumn{4}{|l|}{ Experienced mental health issue in past } \\
\hline 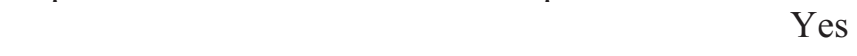 & $87(93.5)$ & & \\
\hline No & $6(6.5)$ & & \\
\hline Missing & 2 & & \\
\hline \multicolumn{4}{|l|}{$\begin{array}{l}\text { Family/friend experienced mental health } \\
\text { issue in past }\end{array}$} \\
\hline 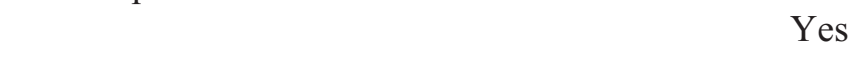 & $90(96.8)$ & & \\
\hline No & $3(3.2)$ & & \\
\hline Missing & 2 & & \\
\hline \multicolumn{4}{|l|}{ Gender } \\
\hline Female & $72(80.0)$ & & \\
\hline Male & $13(14.4)$ & & \\
\hline Non-binary & $5(5.6)$ & & \\
\hline Missing & 5 & & \\
\hline Age & & 30.85 & 9.30 \\
\hline Number of times visiting the social enterprise & & 6.7 & 6.4 \\
\hline
\end{tabular}




\section{Turpin, Shier, \& Scowen (2021)}

Table 6. Descriptive statistics of MAKS variables

\begin{tabular}{|l|c|c|c|}
\hline Variable & Mean & Standard deviation (SD) & Response range \\
\hline MAKS_1 & 1.34 & 0.65 & $1-5$ \\
MAKS_2 & 2.07 & 1.11 & $1-5$ \\
MAKS_3 & 1.73 & 0.81 & $1-5$ \\
MAKS_4 & 1.21 & 0.43 & $1-5$ \\
Mental health stigma & 1.59 & 0.75 & \\
\hline
\end{tabular}

\section{DISCUSSION AND CONCLUSION}

While research has endeavoured to understand and measure mental health accessibility (Elliott \& Hunsley, 2015), it also continues to grapple with the complexity of the concept itself (Grant, Simmons, \& Davey, 2018; Knight \& Winterbotham, 2019). One way researchers and practitioners alike can begin to disentangle this concept is by applying it directly to a service setting (Ganann et al., 2019). In the current study, researchers chose to examine how a novel social enterprise's approach to mental health service provision affects service access for recipients while challenging stigma. While previous studies have identified these outcomes as important aspects in the provision of health services under a social enterprise model, many remain purely conceptual and generally lack analytical approaches that adopt a rigourous mixed-methods analysis (Suchowerska et al., 2020). Further, research has neglected to focus on how social enterprises may accomplish related outcomes, including processes, characteristics, and factors adopted by social enterprise programs that contribute to positive change in the lives of service users and society generally. Lastly, community members are often left out of the research process, neglecting an important stakeholder group within the social enterprise model. These gaps are addressed in the current study, which adopted a case study mixed-methods approach in order to examine the aspects of organizational functioning that lead to social impact by comparing data from counsellors, service users, and community member groups.

Qualitative findings provided a description of barriers to service access while identifying the characteristics of the social enterprise that contribute to outcomes. Figure 1 represents these findings by sample group, revealing themes that were shared between groups as well as those that were identified by one specific sample. The "barriers" column shows how all groups in this study cited the high costs associated with mental health services as a primary barrier; service users explained it as the increased cost of living due to requiring support for mental health, unaffordable rates for talk therapy, living in a precarious financial situation (which is perpetuated by unaddressed mental health needs), and receiving financial support from family and/or friends. Similar barriers to access are cited in related research (Anderson, Howarth, Vainre, Jones, \& Humphrey, 2017; Mojtabai, Chen, Kaufmann, \& Crum, 2014); however, the social enterprise offered a novel solution to this problem by offering low-cost, short-term counselling services to economically disadvantaged service users. This was supported in qualitative findings, as the sliding-scale counselling rate was cited as the most common way in which the social enterprise addressed barriers to mental health service accessibility. Accessibility was also explained as including far more than service affordability. For example, service users and counsellors discussed issues such as cultural appropriateness, service intervention options, language, geographic location, and service environment to also fit within the definition of accessibility. These are important considerations to add to the expanding conceptualization of mental health service accessibility in research and practice. 


\section{Turpin, Shier, \& Scowen (2021)}

Figure 1. Diagram representing qualitative findings by sample group

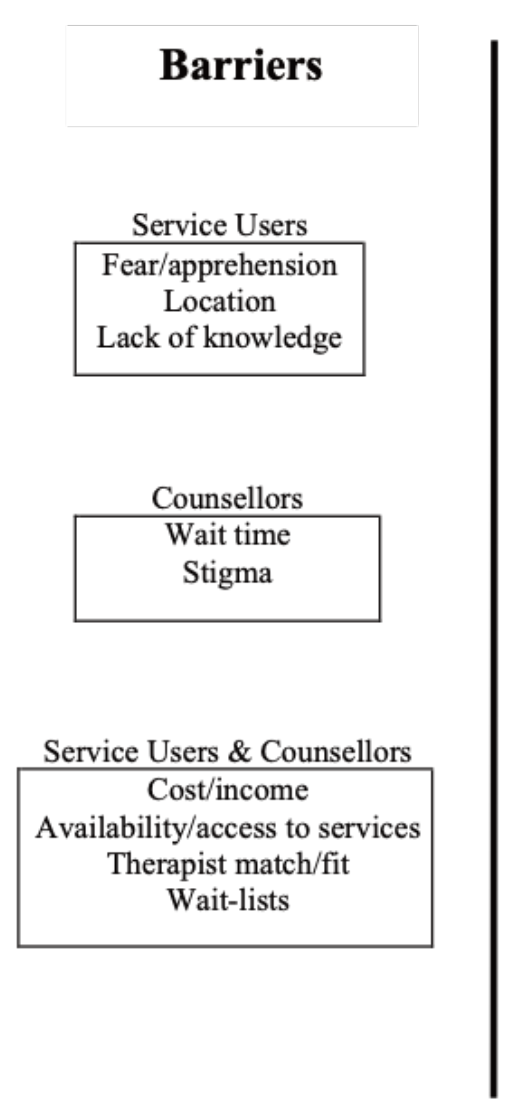

\section{SE Characteristics}

Service Users (SU)
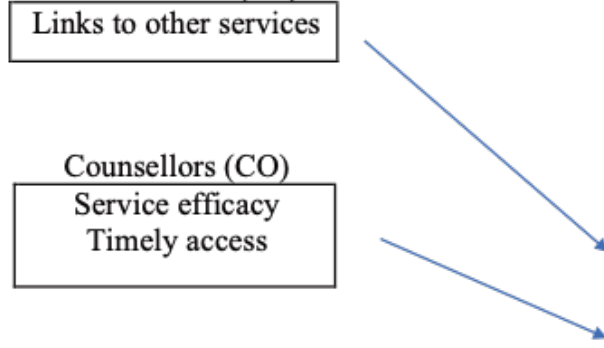

Positive social impact (SU)

Stigma reduction (CO)

Community support (CM)

Community Members (CM)

Supporting community Providing information/knowledge

Increased service access (all)

Respondents also broadly defined a related concept: mental health stigma. Service users explained that stigma can contribute to fear and apprehension when considering seeking support. They described feeling judged and/or feeling as though their mental health challenges were not "bad enough" to warrant service intervention. These findings represent examples of commonly held misconceptions of mental health services, in that respondents may not have understood the wide variety of service options available to address different needs. Further, respondents may not have acknowledged certain symptomology as being problematic or requiring support. This finding aligns with research identifying discrepancies between self-rated symptoms and more objective accounts of mental health issues, such as depression (Cuijpers, Li, Hofmann, \& Andersson, 2010; Pepin et al., 2009) and anxiety (Hoerger, Quirk, Chapman, \& Duberstein, 2012). Regardless, even when the need for mental health support was acknowledged, respondents still felt oppressed by the broadly held negative stigma associated with mental health services.

A novel approach to mixed-methods case study methodology allowed for comparison between respondent groups, and some discrepancies are worth noting. First, service users identified a lack of knowledge regarding mental health services (including suitability and match with therapists, and a poor understanding of different interventions) as a barrier, while counsellors did not. This barrier prevented service users from taking early steps to address mental health concerns, which often exacerbated symptomology. However, counsellors in this study failed to acknowledge how a lack in service user knowledge may reduce mental health service accessibility. This finding alludes to a general need for mental health system navigation support (Godoy, Hodgkin, Robertson, Sham, Druskin, Wambach, Beers, \& Long, 2019; Happell, Wilson, Platania-Phung, \& Stanton, 2016), which is often neglected in primary care settings (Reed, Broussard, Moore, Smith, \& Compton, 2014; Robards et al., 2019). In response to this problem, the social enterprise may choose to address this 


\section{Turpin, Shier, \& Scowen (2021)}

barrier by engaging in more public-facing educational activities that aim to inform individuals about service options. Related activities may encourage people with unaddressed mental health issues to connect with appropriate services. Beyond a general lack of knowledge, this study also found that counsellors cited wait times as a barrier far more than service users did. Interestingly, counsellors were apt to identify this barrier as problematic, explaining that it can cause unaddressed mental health concerns to worsen, while service users did not acknowledge wait times as a primary concern. It may be that service users tolerate longer wait times if the service is a good match, as was the case with the social enterprise. Furthermore, long wait times may be so common that service users normalize them as an expected aspect of mental health services. In other words, long wait times may be common enough that service users have begun to accept them as a "normal" part of accessing services. Therefore, service users would not cite wait times as a barrier because they no longer perceive them as unusual. Researchers did not find any studies seeking to examine this possible link, and any related hypotheses require further empirical analysis before being substantiated.

A final discrepancy was found in data pertaining to the overall social impact of the interventions provided at the social enterprise. Specifically, service users tended to focus on the broader social effects of services, including providing a sense of hopefulness, the development of healthy relationships, and the impact on overall health, while counsellors concentrated on meeting service needs and the impact of the program on service accessibility. Many of the aforementioned outcomes have been identified in previous research as important aspects of the social impact in health-focus social enterprises (Calò et al., 2018, 2019; Macaulay et al., 2017; Roy et al., 2014, 2017). However, the way different stakeholder groups perceive these outcomes has not been adequately examined. The discrepancy witnessed between service users and counsellors in this study offers an important insight. It may follow that service users are more apt to discuss social impact as they reflect on positive changes they associate with their participation in a specific service. However, recognizing these outcomes within the social enterprise is equally important, especially as the organization seeks to identify and measure the ways in which it promotes well-being and addresses social inequities. An outcomes-focused approach is also important as the social enterprise contemplates the scaling of services, which was identified as a primary concern for all respondent groups. Examples of scaling may include providing more counselling sessions, recruiting more practitioners, opening additional locations, and providing more group and/or aftercare therapy services. Findings from this study can be used to identify the social enterprise's most salient outcomes, which can then be leveraged when seeking additional resources for scaling.

Another characteristic of the social enterprise that can be leveraged for scaling pertains to the pro-social aspects largely attached to the organization's brand and public image. Qualitative findings highlight how the image of the social enterprise had a significant effect on a consumer's choice to shop at the storefront. Many community members strongly endorsed supporting local and "ethical" businesses, which the social enterprise was likened to. By shopping at the social enterprise storefront, community members felt as though they were contributing to a social good and aligned their own values with the organization's social mission. Similarly, the social enterprise tapped into altruistic aspects of the community by offering a unique consumer experience. This model has shown early success in supporting the sustainability of the programs offered at the social enterprise and may be replicated in other neighbourhoods or cities. Similar external sources of support are not readily identified in research on social enterprise, possibly because studies often neglect to include community stakeholders as respondents. However, leveraging social support and a deeply imbued sense of social justice altruism within the community may have transformative potential.

Contrary to the hypotheses, no significant relationships were found between demographic characteristics and mental health stigma. There are two possible explanations for these findings. First, it may be that the social enterprise primarily attracts individuals with low mental health stigma. Conceivably, individuals who openly support mental health services and believe in seeking mental health help are more apt to behave on those beliefs by shopping at the social enterprise storefront. Ergo, mean scores on the MAKS scale are relatively low for all items and the latent factor measuring mental 


\section{Turpin, Shier, \& Scowen (2021)}

health stigma, indicating the absence of stigma in the sample. However, variability on these items is also quite low, which may have limited the sensitivity of the scale in identifying significant relationships. It follows that the second explanation for these results is due to limitations in data collection. Demographic statistics reveal how the sample was saturated by previous service users, as well as individuals with experiences of mental health issues (either personally, through a close family member or friend, or both). Research has shown that individuals with first-hand experience of mental health are less likely to hold stigmatizing beliefs about services (Chung, Tse, Lee, \& Chan, 2019; Gulliver, Griffiths, \& Christensen, 2010). Based on related findings, it would be logical to hypothesize that an analysis with a more diverse sample may have resulted in different findings. Researchers in this study hold that both explanations are equally culpable in accounting for the findings in the multivariate analysis and that further research is needed to ascertain a suitable result.

Other limitations of this study include the methodology itself-that is, case study design. Due to the limited scope of case studies, findings can lack generalizability, depending on the sample and structure of the study. However, according to Yin (2014), generalizability is not the primary purpose of case study research. Conversely, robust mixed-methods approaches (such as the one utilized in this study) can lend deep insight into one specific example of a phenomenon, providing details on its complexity in a manner not usually witnessed in large-sample research. Some limitations in data collection must also be noted. Despite the development of a valid and reliable measure of mental health service stigma, non-significant relationships occurred in the multivariate analysis, which may be attributed to the sample demographics, as discussed above. Missing from this analysis are other empirically validated measures (such as social capital or selfefficacy), which could have been included in a more complex model that better captures mental health service accessibility and the experiences of the respondents. However, limitations are to be expected when implementing a novel methodology in an equally unique service environment. The social enterprise examined in this research is not intended to be representative of all nonprofit organizations; researchers have provided an account of a novel approach to mental health services that can be considered when planning to implement similar models. Researchers welcome replication and improvement on the current study and hope to see future case study research adopting analogous frameworks. Results from this study can be assessed and applied to similar service contexts to support the implementation of socially entrepreneurial programs while reducing barriers to mental health service access.

This study provides a useful framework to be applied when assessing the social impact of social enterprise efforts, highlighting the need to assess social impact from the perspectives of a broad range of key stakeholders tied to the social purpose mission of the organization. It also highlights the need to recognize that social impact assessment is complexthe perspectives of organizations and key stakeholder groups may not be fully aligned—and it may not be easy to assess the broader social or societal impact of the enterprise effort. While in this case the mission of the organization aimed to support service accessibility, it also aimed to support transformative social change related to the general population's perspectives on mental health and well-being. It is clear that the social enterprise storefront is catering to a consumer market that is already aligned with this broader social mission. As a result, social enterprises engaging in efforts that aim to create broader systemic change also need to consider finding ways to access their non-consumer markets, possibly through marketing efforts, thereby increasing their social impact.

\section{WEBSITES}

Qualtrics Survey Software. Provo, Utah. https://www.qualtrics.com

Wellbeing Service, https://www.wellbeingnands.co.uk

\section{REFERENCES}

Allen, G.E.K., Kim, B.S.K., Smith, T.B., \& Hafoka, O. (2016). Counseling attitudes and stigma among Polynesian Americans. The Counseling Psychologist, 44(1), 6-27. 


\section{Turpin, Shier, \& Scowen (2021)}

Anderson, J.K., Howarth, E., Vainre, M., Jones, P.B., \& Humphrey, A. (2017). A scoping literature review of servicelevel barriers for access and engagement with mental health services for children and young people. Children and Youth Services Review, 77(full issue), 164-176.

Auger, R.W., Abel, N.R., \& Oliver, B.M. (2018). Spotlighting stigma and barriers: Examining secondary students' attitudes toward school counseling services. Professional School Counseling, 22(1), 1-12.

Bettmann, J.E., Penney, D., Freeman, C.P., \& Lecy, N. (2015). Somali refugees' perceptions of mental illness. Social Work in Health Care, 54(8), 738-757.

Bone, T.A. (2018). Art and mental health recovery: Evaluating the impact of a community-based participatory arts program through artist voices. Community Mental Health Journal, 54(8), 1180-1188.

Brown, R.L., Moloney, M.E., \& Brown, J. (2018). Gender differences in the processes linking public stigma and self-disclosure among college students with mental illness. Journal of Community Psychology, 46(2), 202-212.

Browne, K.C., Chen, J.A., Hundt, N.E., Hudson, T.J., Grubbs, K.M., \& Fortney, J.C. (2019). Veterans self-reported reasons for non-attendance in psychotherapy for posttraumatic stress disorder. Psychological Services. Advance online publication. URL: https://doi.apa.org/doiLanding?doi=10.1037\%2Fser0000375 [January 21, 2020].

Buhariwala, P., Wilton, R., \& Evans, J. (2015) Social enterprises as enabling workplaces for people with psychiatric disabilities. Disability \& Society, 30(6), 865-879.

Calò, F., Roy, M.J., Donaldson, C., Teasdale, S., \& Baglioni, S. (2019). Exploring the contribution of social enterprise to health and social care: A realist evaluation. Social Science \& Medicine, 222(full issue), 154-161.

Calò, F., Teasdale, S., Donaldson, C., Roy, M.J., \& Baglioni, S. (2018) Collaborator or competitor: Assessing the evidence supporting the role of social enterprise in health and social care. Public Management Review, 20(12), 1790-1814.

Chell, E., Nicolopoulou, K., \& Karataş-Özkan, M. (2010). Social entrepreneurship and enterprise: International and innovation perspectives. Entrepreneurship \& Regional Development, 22(6), 485-493.

Chen, K.S., \& Kok, J.K. (2017). Barriers to seeking school counselling: Malaysian Chinese school students' perspectives. Journal of Psychologists and Counsellors in Schools, 27(2), 222-238.

Chung, K., Tse, S., Lee, C., \& Chan, W-M. (2019). Changes in stigma experience among mental health service users over time: A qualitative study with focus groups. Community Mental Health Journal, 55(full issue), 1389-1394.

Conchar, C., \& Repper, J. (2014). "Walking wounded or wounded healer?" does personal experience of mental health problems help or hinder mental health practice? A review of the literature. Mental Health and Social Inclusion, 18(1), 35-44.

Corrigan, P. (2004). How stigma interferes with mental health care. American Psychologist, 59(7), 614-625.

Corscadden, L., Callander, E.J., \& Topp, S.M. (2019). Who experiences unmet need for mental health services and what other barriers to accessing health care do they face? Findings from Australia and Canada. The International Journal of Health Planning and Management, 34(2), 761-772.

Creswell, J.W. (2009). Research design: Qualitative, quantitative, and mixed methods approaches (3d ed.). Thousand Oaks, CA: Sage Publications.

Cuijpers, P., Li, J., Hofmann, S. G., \& Andersson, G. (2010). Self-reported versus clinician-rated symptoms of depression as outcome measures in psychotherapy research on depression: A meta-analysis. Clinical Psychology Review, 30(6), 768-778.

Curtis-Boles, H. (2019) Living in the margins: Intersecting identities and clinical work with black women. Women \& Therapy, 42(3-4), 430-446.

Defourny, J. (2004). Introduction: From third sector to social enterprise. In C. Borzaga \& J. Defourny (Eds.), The emergence of social enterprise (pp.1-28). London, UK: Routledge.

Defourny, J., \& Nyssens, M. (2010). Conceptions of social enterprise and social entrepreneurship in Europe and the United States: Convergences and divergences. Journal of Social Entrepreneurship, 1(1), 32-53. 


\section{Turpin, Shier, \& Scowen (2021)}

Dyrbye, L.N., Eacker, A., Durning, S.J., Brazeau, C., Moutier, C., Massie, F.S, \& Shanafelt, T.D. (2015). The impact of stigma and personal experiences on the help-seeking behaviors of medical students with burnout. Academic Medicine, 90(7), 961-969.

Earlise W., Wiltshire, J., Detry, M., \& Brown, R. (2013). African American men and women's attitude toward mental illness, perceptions of stigma, and preferred coping behaviors. Nursing research, 62, 185-194.

Eamer, A., Fernando, S., \& King, A.E. (2017) Still on the margins: Migration, English language Learning, and mental health in immigrant psychiatric patients. Diaspora, Indigenous, and Minority Education, 11(4), 190-202.

Elliott, K.P., \& Hunsley, J. (2015). Evaluating the measurement of mental health service accessibility, acceptability, and availability in the Canadian community health survey. American Journal of Orthopsychiatry, 85(3), 238-242.

Elnitsky, C.A., Chapman, P.L., Thurman, R.M., Pitts, B.L., Figley, C., \& Unwin, B. (2013). Gender differences in combat medic mental health services utilization, barriers, and stigma. Military Medicine, 178(7), 775-784.

Evans, J., \& Wilton, R. (2019) Well enough to work? Social enterprise employment and the geographies of mental health recovery. Annals of the American Association of Geographers, 109(1), 87-103.

Evans-Lacko, S., Little, K., Meltzer, H., Rose, D., Rhydderch, D., Henderson, C., \& Thornicroft, G. (2010) Development and psychometric properties of the Mental Health Knowledge Schedule. The Canadian Journal of Psychiatry, 55(7), 440-447.

Farmer, J., De Cotta, T., McKinnon, K., Barraket, J., Munoz, S., Douglas, H., \& Roy, M.J. (2016). Social enterprise and wellbeing in community life. Social Enterprise Journal, 12(2), 235-254.

Ferguson, K.M. (2012). Merging the fields of mental health and social enterprise: Lessons from abroad and cumulative findings from research with homeless youths. Community Mental Health Journal, 48(4), 490-502.

Fernando, S. (2005). Multicultural mental health services: Projects for minority ethnic communities in England. Transcultural Psychiatry, 42(3), 420-436.

Fowler, E.A.R., Coffey, B.S., \& Dixon-Fowler, H.R. (2019). Transforming good intentions into social impact: A case on the creation and evolution of a social enterprise. Journal of Business Ethics, 159(3), 665-678.

Ganann, R., Sword, W., Newbold, K.B., Thabane, L., Armour, L., \& Kint, B. (2019). Influences on mental health and health services accessibility in immigrant women with post-partum depression: An interpretive descriptive study. Journal of Psychiatric and Mental Health Nursing, 27(1), 87-96.

Gaston, G.B., Earl, T.R., Nisanci, A., \& Glomb, B. (2016). Perception of mental health services among black Americans. Social Work in Mental Health, 14(6), 676-695.

Glaser, B.G., \& Strauss, A.L. (1967). The discovery of grounded theory: Strategies for qualitative research. New York, NY: Aldine Press.

Goetz, J.P. \& LeCompte, M.P. (1984). Ethnography and qualitative design in educational research. San Diego, CA: Academic Press.

Godoy, L., Hodgkin, S., Robertson, H.A., Sham, E., Druskin, L., Wambach, C.G., Beers, L.S., \& Long, M. (2019). Increasing mental health engagement from primary care: The potential role of family navigation. Pediatrics, 143(4), 1-10.

Grant, K.L., Simmons, M.B., \& Davey, C.G. (2018). Three nontraditional approaches to improving the capacity, accessibility, and quality of mental health services: An overview. Psychiatric Services, 69(5), 508-516.

Griffiths, K.M., Crisp, D.A., Barney, L., \& Reid, R. (2011). Seeking help for depression from family and friends: A qualitative analysis of perceived advantages and disadvantages. BMC Psychiatry, 11, 1-12.

Guetterman, T.C., \& Fetters, M.D. (2018). Two methodological approaches to the integration of mixed methods and case study designs: A systematic review. American Behavioral Scientist, 62(7), 900-918.

Guetterman, T. C., \& Mitchell, N. (2016). The Role of Leadership and Culture in Creating Meaningful Assessment: A Mixed Methods Case Study. Innovative Higher Education, 41(1), 43-57.

Gulliver, A., Griffiths, K.M., \& Christensen, H. (2010). Perceived barriers and facilitators to mental health help-seeking in young people: A systematic review. BMC Psychiatry, 10(1), 113-122. 


\section{Turpin, Shier, \& Scowen (2021)}

Happell, B., Wilson, K., Platania-Phung, C., \& Stanton, R. (2017) Physical health and mental illness: Listening to the voice of carers. Journal of Mental Health, 26(2), 127-133.

Hartley, S.E. (2017). Service users' perceptions of an outreach wellbeing service: A social enterprise for promoting mental health. Community Mental Health Journal, 53(7), 842-851.

Hepworth, N., \& Paxton, S.J. (2007). Pathways to help-seeking in bulimia nervosa and binge eating problems: A concept mapping approach. International Journal of Eating Disorders, 40(6), 493-504.

Hoerger, M., Quirk, S.W., Chapman, B.P., \& Duberstein, P.R. (2012) Affective forecasting and self-rated symptoms of depression, anxiety, and hypomania: Evidence for a dysphoric forecasting bias. Cognition and Emotion, 26(6), 1098-1106.

Holman, D. (2015). Exploring the relationship between social class, mental illness stigma and mental health literacy using British national survey data. Health, 19(4), 413-429.

Hsieh, H-F., \& Shannon, S.E. (2005). Three approaches to qualitative content analysis. Qualitative Health Research, 15(9), 1277-1288.

Hundt, N.E., Helm, A., Smith, T.L., Lamkin, J., Cully, J.A., \& Stanley, M.A. (2018). Failure to engage: A qualitative study of veterans who decline evidence-based psychotherapies for PTSD. Psychological Services, 15(4), 536-542.

Ibaraki, A.Y., \& Hall, G.C.N. (2014). The components of cultural match in psychotherapy. Journal of Social and Clinical Psychology, 33(10), 936-953.

Jordans, M., Luitel, N., Garman, E., Kohrt, B., Rathod, S., Shrestha, P., ... Patel, V. (2019). Effectiveness of psychological treatments for depression and alcohol use disorder delivered by community-based counsellors: Two pragmatic randomised controlled trials within primary healthcare in Nepal. British Journal of Psychiatry, 215(2), 485-493.

Kernot, C. (2009). Social enterprise: A powerful path to social inclusion. Centre for Social Impact. URL: http:// library.bsl.org.au/jspui/bitstream/1/2335/1/SocialEnterprise_PowerfulPath.pdf [January 21, 2020].

Kidd, S.A., Kerman, N., Cole, D., Madan, A., Muskat, E., Raja, S., Rallabandi, S., \& McKenzie, K. (2015). Social entrepreneurship and mental health intervention: A literature review and scan of expert perspectives. International Journal of Mental Health and Addiction, 13(6), 776-787.

Kne, A., Zierhut, H., Baldinger, S., Swenson, K.K., Mink, P., Veach, P.M., \& Tsai, M.L. (2017). Why is cancer genetic counseling underutilized by women identified as at risk for hereditary breast cancer? Patient perceptions of barriers following a referral letter. Journal of Genetic Counseling, 26(4), 697-715.

Knifton, L. (2012). Understanding and addressing the stigma of mental illness with ethnic minority communities. Health Sociology Review, 21(3), 287-298.

Knight, B,G., \& Winterbotham, S. (2019). Rural and urban older adults' perceptions of mental health services. Aging \& Mental Health, 24(6), 978-984.

Kowalewski, K., McLennan, J.D., \& McGrath, P.J. (2011). A preliminary investigation of wait times for child and adolescent mental health services in Canada. Journal of the Canadian Academy of Child and Adolescent Psychiatry, 20(2), 112-119.

Krupa, T., Sabetti, J., \& Lysaght, R. (2019). How work integration social enterprises impact the stigma of mental illness. Social Enterprise Journal, 15(4), 475-494.

Lamsal, R., Stalker, C.A., Cait, C-A., Riemer, M., \& Horton, S. (2018) Cost-effectiveness analysis of single-session walk-in counselling. Journal of Mental Health, 27(6), 560-566.

Lee, E.-J., Ditchman, N., Fong, M.W.M., Piper, L., \& Feigon, M. (2014). Mental health service seeking among Korean international students in the United States: A path analysis. Journal of Community Psychology, 42(6), 639-655.

Little, S.H., Motohara, S., Miyazaki, K., Arato, N., \& Fetters, M.D. (2013). Prenatal group visit program for a population with limited English proficiency. The Journal of the American Board of Family Medicine, 26(6), 728-737.

Loewenthal, D., Mohamed, A., Mukhopadhyay, S., Ganesh, K., \& Thomas, R. (2012). Reducing the barriers to accessing psychological therapies for Bengali, Urdu, Tamil and Somali communities in the UK: Some implications for training, policy and practice. British Journal of Guidance \& Counselling, 40(1), 43-66. 


\section{Turpin, Shier, \& Scowen (2021)}

Lynch, L., Long, M., \& Moorhead, A. (2018). Young men, help-seeking, and mental health services: Exploring barriers and solutions. American Journal of Men's Health, 12(1), 138-149.

Lysaght, R., Krupa, T., \& Bouchard, M. (2018). The role of social enterprise in creating work options for people with intellectual and developmental disabilities. Journal on Developmental Disabilities, 23(3), 18-30.

Macaulay, B., Roy, M.J., Donaldson, C., Teasdale, S., \& Kay, A. (2018). Conceptualizing the health and well-being impacts of social enterprise: a UK-based study. Health Promotion International, 33(5), 748-759.

Mandiberg, J.M (2016) Social enterprise in mental health: An overview. Journal of Policy Practice, 15(1-2), 5-24.

Mandiberg, J.M., \& Edwards, M. (2016) Business incubation for people with severe mental illness histories: The experience of one model. Journal of Policy Practice, 15(1-2), 82-101.

Martin, J.M. (2010). Stigma and student mental health in higher education. Higher Education Research \& Development, 29(3), 259-274.

McKeown, E., Weir, H., Berridge, E-J., Ellis, L., \& Kyratsis, Y. (2016). Art engagement and mental health: Experiences of service users of a community-based arts programme at Tate Modern, London. Public Health, 130(full issue), 29-35.

McMurtry, J., \& Brouard, F. (2015). Social enterprises in Canada: An introduction. Canadian Journal of Nonprofit and Social Economy Research, 6(1), 6-24.

Miles, M.B., \& Huberman, A.M. (1994). An expanded sourcebook: Qualitative data analysis (2nd Ed.). Thousand Oaks, CA: Sage Publications.

Mojtabai, R., Chen, L-Y., Kaufmann, C.N., \& Crum, R.M. (2014). Comparing barriers to mental health treatment and substance use disorder treatment among individuals with comorbid major depression and substance use disorders. Journal of Substance Abuse Treatment, 46(2), 268-273.

Morgan, A.J., Reavley, N.J., Jorm, A.F., \& Beatson, R. (2017). Discrimination and support from friends and family members experienced by people with mental health problems: Findings from an Australian national survey. Social Psychiatry Psychiatric Epidemiology, 52, 1395-1403.

Mosher, C.E., Winger, J.G., Hanna, N., Jalal, S. I., Fakiris, A.J., Einhorn, L.H...\& Champion, V.L. (2014). Barriers to mental health service use and preferences for addressing emotional concerns among lung cancer patients. Psycho-Oncology, 23(7), 812-819.

Munoz, S., Farmer, J., Winterton, R., \& Barraket, J. (2015). The social enterprise as a space of well-being: An exploratory case study. Social Enterprise Journal, 11(3), 281-302.

Oats, J., \& Drey, N. (2017). "Your experiences were your tools." How personal experience of mental health problems informs mental health nursing practice. Psychiatric and Mental Health Nursing, 24(7), 471-479.

Olinsson, S.B. (2017). Social entrepreneurship-committing theory to practice. Journal of Social Entrepreneurship, 8(2), 225-247.

Onghena, P., Maes, B., \& Heyvaert, M. (2019). Mixed methods single case research: State of the art and future directions. Journal of Mixed-Methods Research, 13(4), 461-480.

Onwuegbuzie, A.J., \& Leech, N.L. (2010). Generalization practices in qualitative research: A mixed methods case study. Quality \& Quantity, 44, 881-892.

Owens, G.P., Rogers, S.M., \& Whitesell, A.A. (2011). Use of mental health services and barriers to care for individuals on probation or parole. Journal of Offender Rehabilitation, 50(1), 37-47.

Palmer, D., \& Ward, K. (2007). 'Lost': Listening to the voices and mental health needs of forced migrants in London. London, Medicine, Conflict and Survival, 23(3), 198-212.

Pantalone, D.W., Scanlon, M.L., Brown, S.M., Radhakrishnan, B., \& Sprague, C. (2018). Unmet mental health and social service needs of formerly incarcerated women living with HIV in the deep south. Journal of the Association of Nurses in AIDS Care, 29(5), 712-727.

Pedersen, E.R., \& Paves, A.P. (2014). Comparing perceived public stigma and personal stigma of mental health treatment seeking in a young adult sample. Psychiatry Research, 219(1), 143-150. 


\section{Turpin, Shier, \& Scowen (2021)}

Pepin, R., Segal, D.L., \& Coolidge, F.L. (2009). Intrinsic and extrinsic barriers to mental health care among communitydwelling younger and older adults. Aging \& Mental Health, 13(5), 769-777.

Pfeiffer, P.N., Bowersox, N., Birgenheir, D., Burgess, J., Forman, J., \& Valenstein, M. (2016). Preferences and barriers to care following psychiatric hospitalization at two veterans affairs medical centers: A mixed methods study. The Journal of Behavioral Health Services \& Research, 43(1), 88-103.

Phalen, P.L. (2016). Psychological distress and rates of health insurance coverage and use and affordability of mental health services, 2013-2014. Psychiatric Services, 68(5), 512-515.

Phillips, W., Lee, H., Ghobadian, A., O’Regan, N., \& James, P. (2015). Social innovation and social entrepreneurship. Group \& Organization Management, 40(3), 428-461.

Presley, S., \& Day, S.X. (2019). Counseling dropout, retention, and ethnic/language match for Asian Americans. Psychological Services, 16(3), 491-497.

Reed, T.A., Broussard, B., Moore, A., Smith, K.J., \& Compton, M.T. (2014). Community navigation to reduce institutional recidivism and promote recovery: Initial evaluation of opening doors to recovery in southeast Georgia. Psychiatric Quarterly, 85, 25-33.

Robards, F., Kang, M., Steinbeck, K.,Hawke, C., Jan, S., Sanci, L., Liew, Y.Y...\& Ungerwood, T. (2019). Health care equity and access for marginalised young people: A longitudinal qualitative study exploring health system navigation in Australia. International Journal for Equity in Health, 18, 1-14.

Robertson, S., Carpenter, D., Donovan-Hall, M., \& Bartlett, R. (2019). Using lived experience to develop a personal narrative workshop programme in order to aid mental health recovery. Journal of Mental Health, 29(4), 483-491.

Robinson, M.A., \& Brewster, M.E. (2016). Understanding affiliate stigma faced by heterosexual family and friends of LGB people: A measurement development study. Journal of Family Psychology, 30(3), 353-363.

Roy, M.J., Baker, R., \& Kerr, S. (2017). Conceptualizing the public health role of actors operating outside of formal health systems: The case of social enterprise. Social Science \& Medicine, 172, 144-152.

Roy, M.J., Donaldson, C., Baker, R., \& Kerr, S. (2014). The potential of social enterprise to enhance health and wellbeing: A model and systematic review. Social Science \& Medicine, 123, 182-193.

Rughani, J., Deane, F.P., \& Wilson, C.J. (2011). Rural adolescents' help-seeking intentions for emotional problems: The influence of perceived benefits and stoicism. Australian Journal of Rural Health, 19(2), 64-69.

Saechao, F., Sharrock, S., Reicherter, D., Livingston, J.D., Aylward, A., Whisnant, J., Koopman, C., \& Kohli, S. (2012). Stressors and barriers to using mental health services among diverse groups of first-generation immigrants to the United States. Community Mental Health Journal, 48(1), 98-106.

Saha, S., Fernandez, A., \& Perez-Stable, E. (2007). Reducing language barriers and racial/ethnic disparities in health care: An investment in our future. Journal of General Internal Medicine, 22(2), 371-372.

Schnyder, N., Michel, C., Panczak, R., Ochsenbein, S., Schimmelmann, B.G., \& Schultze-Lutter, F. (2018). The interplay of etiological knowledge and mental illness stigma on healthcare utilisation in the community: A structural equation model. European Psychiatry, 51, 48-56.

Sevelius, J.M., Patouhas, E., Keatley, J.G., \& Johnson, M.O. (2014). Barriers and facilitators to engagement and retention in care among transgender women living with human immunodeficiency virus. Annals of Behavioral Medicine, 47(1), 5-16.

Shannon, P.J., Wieling, E., Simmelink-McCleary, J., \& Becher, E. (2015). Beyond stigma: Barriers to discussing mental health in refugee populations. Journal of Loss and Trauma, 20(3), 281-296.

Smith, B.R., \& Stevens, C.E. (2010). Different types of social entrepreneurship: The role of geography and embeddedness on the measurement and scaling of social value. Entrepreneurship \& Regional Development, 22(6), 575-598.

Sotskova, A., Woodin, E., \& St. Cyr, K. (2016) Understanding the role of group cohesion and group alliance in a secular peer support group for recovery from substance misuse. Journal of Groups in Addiction \& Recovery, 11(2), 137-154 


\section{Turpin, Shier, \& Scowen (2021)}

Suchowerska, R., Barraket, J., Qian, J., Mason, C., Farmer, J., Carey, G., Campbell, P., \& Joyce, A. (2020). An organizational approach to understanding how social enterprises address health inequities: A scoping review. Journal of Social Entrepreneurship, 11(3), 257-281.

Townsend, L., Musci, R., Stuart, E., Heley, K., Beaudry, M.B., Schweizer, R.N., Ruble, A. ... Wilcox, H. (2019). Gender differences in depression literacy and sigma after a randomized controlled evaluation of a universal depression education program. Journal of Adolescent Health, 64(4), 472-477.

Turpin, A., \& Shier, M.L. (2019). Social entrepreneurial orientation in human service organizations: A scoping review. Human Service Organizations: Management, Leadership \& Governance, 44(2), 144-168.

Turpin, A., \& Shier, M.L. (2017) Peer support and substance use disorder treatment: Benefits and barriers for intrapersonal development in longer-term treatment programs. Journal of Groups in Addiction \& Recovery, 12(2-3), 117-134.

UyBico, S.J., Pavel, S., \& Gross, C.P. (2007). Recruiting vulnerable populations into research: A systematic review of recruitment interventions. Journal of general internal medicine, 22(6), 852-863.

Wei, Y., Carr, W., Alaffe, R., \& Kutcher, S. (2019). Mental health literacy development: Application of online and inperson professional development for preservice teachers to address knowledge, stigma, and help-seeking intentions. Canadian Journal of Behavioural Science, 52(2), 107-114.

Van Wijk, E. (2014). Recruitment and retention of vulnerable populations: Lessons learned from a longitudinal qualitative study. Qualitative Report, 19(28), 1-21.

Yin, R.K. (2014). Case study research: Design and methods (5th ed.). Thousand Oaks, CA: Sage

Yousaf, O., Grunfeld, E.A., \& Hunter, M.S. (2015). A systematic review of the factors associated with delays in medical and psychological help-seeking among men. Health Psychology Review, 9(2), 264-276.

Zahra, S., \& Wright, M. (2011). Entrepreneurship's next act. Academy of Management Perspectives, 25(4), 67-83.

\section{ABOUT THE AUTHORS / L'AUTEURS}

Aaron Turpin is a PhD Candidate at the Factor-Inwentash Faculty of Social Work, University of Toronto. Email: aaron.turpin@mail.utoronto.ca

Micheal Shier is Associate Professor at the Factor-Inwentash Faculty of Social Work, University of Toronto. Email: m.shier@utoronto.ca

Kate Scowen is Executive Director at Hard Feelings Mental Health. Email: kate@hardfeelings.org 